\title{
Creating Provincial and Territorial Search Filters to Retrieve Studies Related to Canadian Indigenous Peoples from Ovid MEDLINE ${ }^{1}$
}

\author{
Sandy Campbell, Marlene Dorgan, and Lisa Tjosvold
}

\begin{abstract}
Introduction: Performing systematic review searches related to Canadian Indigenous peoples (First Nations, Inuit, and Métis), particularly in areas of public health, is difficult because Medical Subject Headings (MeSH) terms for both Indigenous peoples and geography do not retrieve all relevant articles in Ovid MEDLINE. Text-word searching for Canadian Indigenous peoples presents challenges in the varieties of names, spellings, and languages. A series of Canadian Indigenous peoples filters were designed to retrieve larger numbers of relevant articles. Objectives: The objectives of this work were $(i)$ to create first-generation search filters that retrieve studies from the Ovid MEDLINE database related to Canadian Indigenous peoples, (ii) to determine whether or not the filters retrieve more records than do searches using the MeSH headings alone, and (iii) to determine how many of the additional records are relevant. Methods: Key terms describing both Canadian Indigenous peoples and Canadian geography were identified using government, historical, and ethnographic publications. Name lists included current and historical names in multiple languages, as well as local and settlement names, and names of linguistic groups. Filters, employing both text-word and $\mathrm{MeSH}$ terms were created for each province and territory, excluding Prince Edward Island. Search results were reviewed for false recalls related to terms with multiple meanings and groups of people whose lands straddle provincial and territorial borders. Revised searches were refined with additional terminology that implies the presence of Indigenous peoples. Duplicate records were removed from both the MeSH searches and the filter searches. Results from the MeSH searches were then removed from the results of the filter searches. The remaining results were analyzed for relevance. Results: Twelve Ovid MEDLINE filters were created and the challenges involved in creating them were documented. The filters increased recall by 58 articles, $464 \%$ over MeSH searches alone. Of the additional articles retrieved, $28(100 \%)$ met the criteria for relevance. Discussion: The lists of challenges identified in the filter creation will assist other searchers in developing similar filters. The filters allow searchers to retrieve substantially more articles than is currently possible with the MeSH terms alone.
\end{abstract}

\section{Introduction}

Performing systematic review searches related to Canadian Indigenous peoples, particularly in areas of public health, is difficult because MeSH terms for both Indigenous peoples and geography do not retrieve all relevant articles in MEDLINE. Text-word searching for Canadian Indigenous peoples presents challenges in the varieties of names, spellings, and languages. A series of Canadian Indigenous peoples filters were designed to retrieve larger numbers of relevant articles.

\section{Objectives}

The objectives of this work were (i) to create firstgeneration search filters that retrieve studies from the Ovid
MEDLINE database related to Canadian Indigenous peoples, (ii) to determine whether or not the filters retrieve more records than do searches using the MeSH headings alone, and (iii) to determine how many of the additional records are relevant.

\section{Background}

Searching comprehensively in the health literature for studies related to Indigenous peoples in Canada presents many challenges. Additionally, because health care administration and delivery fall under provincial jurisdiction in Canada, researchers frequently undertake studies related to the health of Indigenous peoples within a specific province or territory. To streamline and simplify these searches, the research team undertook to create hedges or

Sandy Campbell, ${ }^{2}$ Marlene Dorgan, and Lisa Tjosvold. John W. Scott Health Sciences Library, University of Alberta, 2 K3.28 Walter C. Mackenzie Health Sciences Centre, Edmonton, AB T6G 2R7.

${ }^{1}$ This paper is peer reviewed.

${ }^{2}$ Corresponding author (e-mail: sandy.campbell@ualberta.ca). 
filters to retrieve studies related to Indigenous peoples in all of Canada's territories and provinces. The first suite of filters has been designed for the Ovid MEDLINE database, and can be accessed online at the University of Alberta's Education and Research Archive (ERA).

Search filters or hedges "are pre-tested strategies that identify the higher quality evidence from the vast amounts of literature indexed in the major medical databases" [1]. First-generation filters are "subjectively derived, based on librarian searcher expertise, relying on knowledge of the database structure, content and thesaurus, along with the clinicans' subject knowledge. Measures of how effective the search filter performs on an independent set of relevant records are not calculated" [2]. Klatt observed that "the use of a subject hedge can greatly improve the quality and accuracy of a mediated search on MEDLINE or any other database" [3]. Although methodological filters are readily available [4], less work has been done in creating geographically based filters or filters that identify publications related to Indigenous peoples. Geographic filters have been developed, for example, for Africa [5] and the European Union [6]. Murray [7] created a filter to retrieve all materials related to the Circumpolar North, but no geographic filters for the Canadian provinces and territories have been created. Similarly, some work on filters to identify studies related to Indigenous peoples has been done. For example, Sladek et. al. recently tested a filter to identify Australian Aboriginal and Torres Strait Islander health literature [8]. In the Canadian context, Guistini [9] has created a list of useful Indigenous-related terms that could be combined to create a filter. However, the purpose of this research project was to create "cut and paste" filters that anyone could copy into the Ovid MEDLINE search box and execute immediately.

Some of the challenges involved in using MeSH terms to identify studies related to Indigenous peoples in Ovid MEDLINE are described in the literature [10]. Among these, the most critical is that the two primary MeSH terms that include Canadian Indigenous peoples (Indians, North American, and Inuits) are missing from many relevant records. These deficiencies may be attributed to the following:

(i) The records have no subject headings attached. This may be because the articles are too new to be indexed or because they were added to the database when the journal in which they were published started to be indexed, but no back-indexing was done.

(ii) The records are indexed at too high a level in the $\mathrm{MeSH}$ tree (e.g., articles indexed to the broader heading Genetic Groups, which includes many groups in Canada, in addition to Indigenous peoples, instead of using the more specific heading).

(iii) No indexing at all was applied to represent ethnic, cultural, or linguistic groups in a study.

(iv) The Indigenous peoples aspect of the study was not considered to be a primary focus of the study and, therefore, was not reflected in the subject headings.

(v) Incorrect subject headings were applied.
Articles related to Canadian Indigenous peoples are sometimes indexed using four additional MeSH terms: "Health Services, Indigenous"; "Medicine, Traditional"; "Shamanism"; and "Ethnopharmacology". Like the primary two headings, these may also be applied inconsistently and some are also applied to other groups including Indigenous peoples outside Canada.

Similarly, geographic indexing is often missing or is too high level (e.g., North America instead of Canada) to be useful to retrieve all of the articles related to a specific geographic area. Occasionally the indexing is incorrect (e.g., MEDLINE record 23157729 is about Australian subjects [11] but is indexed to Northwest Territories).

\section{Methods}

\section{Process for creating the filters}

A team of three practising health librarians created the filters. Searches were executed between 1 May 2013 and 20 December 2013 on the Ovid MEDLINE database (Ovid MEDLINE In-Process and Other Non-Indexed Citations, Ovid MEDLINE Daily, and Ovid MEDLINE 1946 to Present). For each filter, with the exception of Nunavut, the librarians used the following process with no limits applied.

(i) Team members searched a variety of sources for both Indigenous and geographic terms relevant to the particular province or territory. These included atlases, maps, ethnographic works, provincial and federal government web sites, Indigenous organizations' web sites, and other web sites.

(ii) Team members searched relevant $\mathrm{MeSH}$ terms, broad Indigenous group or linguistic names, and terms that implied Indigenous people that were all qualified, where appropriate, with provincial or territorial geographic headings or text-word terms.

(iii) Team members searched names of Indigenous groups or terms specific to the province or territory.

(iv) Team members searched Indigenous place names including settlement names and reserves specific to the province or territory.

(v) Team members searched Indigenous place names that also occur outside of Canada and qualified them with Canadian geographic terminology.

(vi) Filters were constructed employing Boolean operators, adjacency, truncation, and nested logic as appropriate to create a single line search that can be cut and pasted into the Ovid MEDLINE search box.

(vii) Results were reviewed to identify terms that retrieve high levels of irrelevant materials. Those terms were adjusted in the search. Where appropriate, specific terms that introduced too much irrelevant material were removed from the search using the "NOT" operator.

Development of the Nunavut filter followed the same process, except that it is based solely on geographic terms. 
Recent Statistics Canada statistics [12] show that the population of Nunavut is largely $(86.3 \%)$ Indigenous, so health studies in Nunavut are likely to be about Indigenous peoples. Studies done prior to Nunavut's creation in 1999 are captured using town and settlement names.

\section{Testing the filters}

The filters were tested to determine whether or not they retrieved more relevant references in Ovid MEDLINE than did relevant combinations of $\mathrm{MeSH}$ terms and geographic headings using the following process:

(i) Initial searches were conducted using $\mathrm{MeSH}$ terms and geographic headings only. Figure 1 shows an example search conducted on 5 February 2014.

(ii) Searches were conducted using the filters.

(iii) Duplicate records were removed using the "remove duplicates from $\mathrm{xx}$ " command, where " $\mathrm{xx}$ " is the line number in the search.

(iv) The results of the MeSH searches were then removed from the results of the filtered searches.

(v) Titles and abstracts of the remaining results were reviewed for relevance to Indigenous peoples, health subjects. and geographic focus. Full articles were not reviewed.

Relevance was defined as including all of $(i)$ reference to an Indigenous group, (ii) a reference to a healthrelated topic, and (iii) a clear indication that the study included people in the province or territory under study. Health-related topics were broadly interpreted to include not only clinical, genetic, and epidemiological studies, but also health policy, health administration, and environmental health. Studies of environmental pollutants were included if there was an indication that the pollutant was entering human food and water sources. Review of the records for relevance was done either by the authors or by a graduate-level assistant who was trained for this task.

\section{Results}

\section{Filter development}

The result of the filter development phase of the project was 12 Ovid MEDLINE filters representing all Canadian provinces and territories, with the exception of Prince Edward Island where very few studies contain words that indicate the presence of Indigenous peoples. The versions of the filters used for the analysis in this paper are permanently archived in the University of Alberta's institutional repository ERA. The filters were also published as independent documents on a University of Alberta Libraries LibGuide, "Health Sciences Search Filters," where they may be updated and revised where necessary. Each of the filters includes references to the sources used for the identification of relevant terms as well as notes for searchers.

In addition to the filters themselves, this project identified specific challenges involved in searching for both Indigenous peoples and geographic content in the Canadian context, and it confirmed the challenges identified by Mueller-Alexander and Seaton [13] and this team's earlier exploratory work [14].

\section{Challenges in text-word searching for Indigenous peoples}

(i) Although a study may refer to a specific group of Indigenous peoples who are resident within a particular province, authors may use general terms such as First Nations, Indigenous, Aboriginal, Métis, Amerindian, or Inuit, rather than specific group names to describe the study subjects making it

Fig. 1. Example of MeSH subject and geographic heading search.

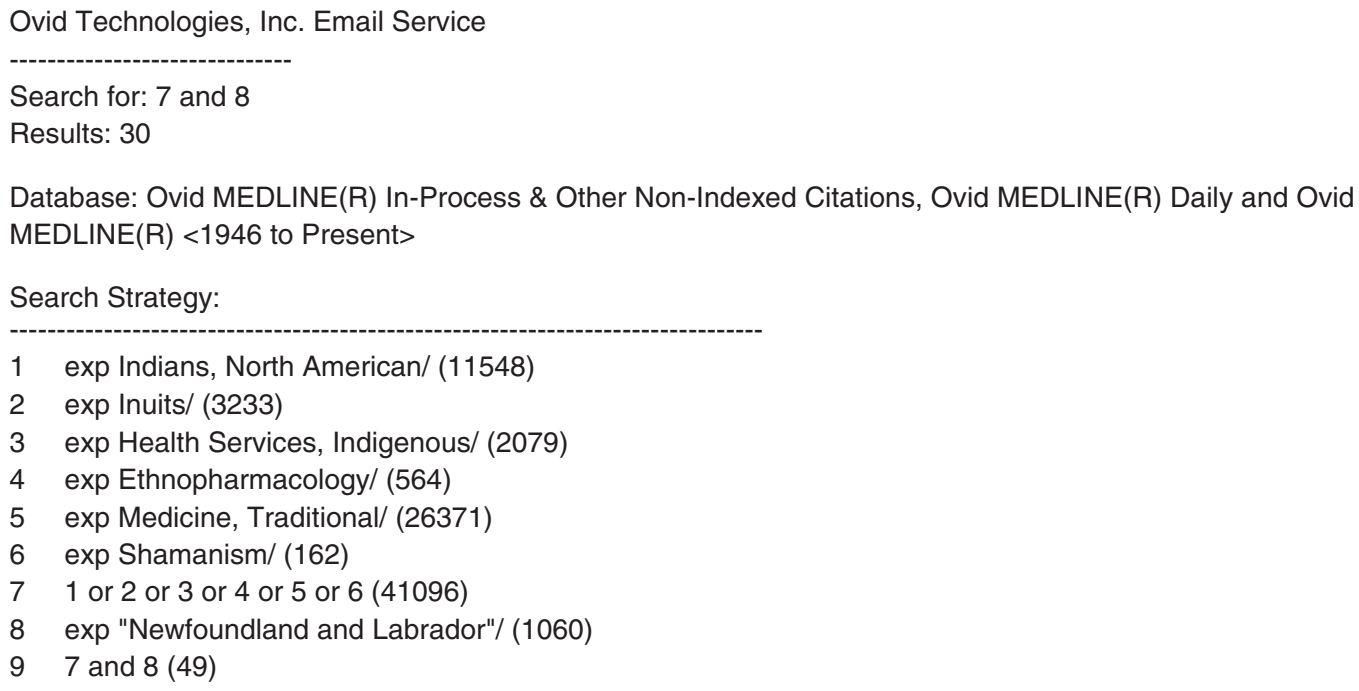


impossible to use the group's name to identify specific groups.

(ii) The terms "Native", "Aboriginal", "Indigenous" and "Indian" have historically been used to identify Canadian Indigenous peoples. However, the terms "native", "aboriginal," and "indigenous" also retrieve large numbers of references to plant and animal species. The term "Indian" retrieves studies related to people whose ethnic origin or country of birth is India.

(iii) Within Canada, many groups overlap one or more provincial, territorial, or international border, which makes it more difficult to isolate studies about these people within a province or territory. (e.g., Cree, Gwich'in, Naskapi).

(iv) The names of groups of Indigenous peoples may be recorded in various languages, (e.g., Inuit, Eskimo, Esquimaux).

(v) The names of groups of Indigenous peoples have variant spellings or may be spelled incorrectly (e.g., Gwich'in, Kutchin, Gwitchin).

(vi) The names of Indigenous groups may have changed over time (e.g., Dogrib-Tlicho).

(vii) Terms for objects or concepts closely associated with Indigenous peoples (e.g., treaties, reserves, countryfood) are sometimes the best indicators of Indigenous content in a study.

(viii) Individual groups may be identified by their linguistic family (e.g., Algonquian), geographic subgroups (e.g., Woodland Cree), legal group names (Inuvialuit Settlement Area), and band or tribal names (e.g., Bigstone Cree).

(ix) In some parts of Canada, the population is predominantly Indigenous, so the use of a unique place name (e.g., Sach's Harbour), can stand as a surrogate for terms relating to Indigenous peoples.

(x) The names of some Indigenous groups are the same as Geographic terms (e.g., Bella Coola is historically the name of a People and also of a town and a valley).

(xi) Indigenous names have been used to name things or have been incorporated into trade names that are also present in the health literature (e.g., Iroquois homeobox genes).

\section{Challenges in text-word searching for geographic terms related to Canadian Indigenous peoples}

(i) Place names have changed over time (e.g., the community of Hobbema, Alberta became Maskwacis, Alberta effective 1 January 2014. [15]).

(ii) Place names may have spelling variants or common errors in spelling (e.g., Hudson's Bay and Hudson Bay).

(iii) Place names are often replicated outside the province of interest (e.g., Deer Lake occurs in several provinces).

(iv) Place names occur in the health literature in nongeographic contexts (e.g., Banff Test).

(v) Some place names have other meanings that are significant in the health literature (e.g., Gamblers, Manitoba).

(vi) Geographic boundaries change over time. (e.g., all locations in Nunavut were in the Northwest Territories before 1999).

(vii) Authors may identify Indigenous peoples in large geographic areas (e.g., Mackenzie Valley Basin, Ellesmere Island, etc.) or very small ones (Buffalo Narrows, SK). An individual place may be identified in the literature as any one of: a band, a health unit, a health authority, a town, a settlement area, a health region, a province, or a geographic region requiring the inclusion of many terms in the filters.

Table 1 documents the results of the test searches. All of the filters retrieved more references than the standard

Table 1. Comparison of MeSH and filtered Ovid MEDLINE searches for publications related to Canadian Indigenous peoples by province or territory.

\begin{tabular}{|c|c|c|c|c|c|}
\hline Province or territory & $\begin{array}{l}\text { MESH } \\
\text { search }\end{array}$ & $\begin{array}{l}\text { Filter } \\
\text { search }\end{array}$ & Difference $(\%)$ & $\begin{array}{l}\text { Relevant of additional publications } \\
\text { retrieved from the filter search }(\%)\end{array}$ & Date searched \\
\hline British Columbia & 333 & 643 & $366(110)$ & 69 & 17 December 2013 \\
\hline Saskatchewan & 137 & 231 & $118(86)$ & 77 & 17 December 2012 \\
\hline Manitoba & 237 & 410 & $173(73)$ & 87 & 12 November 2013 \\
\hline Ontario & 304 & 934 & $630(207)$ & 28 & 19 December 2013 \\
\hline Nova Scotia & 15 & 27 & $12(80)$ & 92 & 12 November 2013 \\
\hline Newfoundland and Labrador & 48 & 102 & $54(112)$ & 100 & 12 November 2013 \\
\hline Nunavut & 82 & 463 & $381(464)$ & 83 & 11 December 2013 \\
\hline Northwest Territories & 138 & 457 & $319(231)$ & 64 & 20 December 2013 \\
\hline Yukon Territory & 19 & 82 & $63(332)$ & 83 & 20 December 2013 \\
\hline
\end{tabular}

Note: Percentages were rounded to the nearest whole number. Prince Edward Island is not included because all combinations of terms relating to PEI and Indigenous peoples resulted in only two articles. 
MeSH and geographic subject heading search. Increases in retrieval ranged from $73 \%$ to $464 \%$. Relevance of the additional references ranged from $28 \%$ to $100 \%$.

\section{Discussion}

Because these are first-generation search filters, they are subjectively developed and are not tested against an external gold standard. However, it is clear that all of the filters retrieved more studies related to Indigenous peoples' health than the MeSH terms alone and many of those additional results are relevant.

Given the limitations of the MeSH terms that are outlined in the Background section, it is not surprising that detailed search filters that use a combination of $\mathrm{MeSH}$ terms and text words retrieve additional relevant materials. The volume of relevant articles that are missed by standard indexing is noteworthy. Knowing that "conducting a thorough search to identify relevant studies is a key factor in minimizing bias in the review process" [16], searchers will be able to use these filters to more efficiently conduct comprehensive searches for articles about Indigenous peoples in Canadian provinces and territories.

Each of the filters is a unique balance of relevance and recall defined by the librarian who designed it and the filters reflect the nuances of the presence of Indigenous peoples in each province or territory. The filters have been constructed for practical use within the searchers' day-today work, with the understanding that they will be used in conjunction with other health concepts, so the balance between recall and relevance leans towards recall. All of the filters contain terms and names that currently retrieve zero results. This is a purposeful inclusion that anticipates that, with the increase in health research related to Indigenous Canadians, future studies may incorporate these terms.

\section{Limitations of the filters}

The filters have limitations. First, they are complex and if executed over slow connections, it may take a long time to complete their retrieval. Users working with slow connections may have to search sections separately to avoid time-out situations. Second, the filters are designed to retrieve articles that are relevant to the specific provinces and territories. However, many studies indexed in MEDLINE deal with the health of Indigenous peoples in Canada but give no indication of where those people reside. Many studies, particularly at the national scale include the phrase "Aboriginal, Métis, and Inuit" but do not supply precise geographic information. These cannot be captured by provincial and territorial filters. Third, groups of Indigenous peoples and even members of the same families are found in different provinces and territories. Traditional lands of specific groups often straddle borders. Because the filters retrieve studies based on jurisdiction, researchers studying large groups of people will find that they need to employ several of the filters to locate all studies relevant to one group of Indigenous peoples. Finally, none of the filters is perfect. They are being revised, refined, and rewritten as they are used. The filters presented with this paper represent a snapshot, freezing the filters in time for the purpose of analysis.

\section{Limitations of this study}

This study itself has limitations. First, no attempt, apart from the sequence of steps described in the Methods section, was made to standardize the search development processes or styles of the searchers. Differences in relevance levels among the searches can be attributed to the differences in the searching styles, training, and experience of the different searchers. The study could be enhanced by having searchers test and review each other's filters. Second, these are first-generation filters; therefore, no gold standard was developed for precision or recall testing. Relevance testing was based on guidelines described in the Methods section, but even with guidelines the determination of relevance is a subjective act. Four different reviewers made determinations of relevance, so the relevance numbers should be read as indicative rather than absolute. Third, because the determination of relevance was based on the title and abstract rather than the full text, closer analysis of the texts could change the numbers of relevant studies.

\section{Conclusion}

This work is a first attempt at creating comprehensive filters to retrieve studies related to Indigenous peoples by Canadian province or territory in any subject area. The documentation of the challenges involved in creating filters for the Ovid MEDLINE database will be useful in creating similar filters in other subject areas and for other databases and platforms. These filters retrieve more studies related to Indigenous peoples in any province or territory than do the $\mathrm{MeSH}$ and geographic headings alone. The proportion of relevant studies among the additional studies retrieved varies. The filters demonstrate that if text-words are not included in searches for Indigenous people in Canada, many studies will be missed.

The filters continue to be refined and updated. Updated versions of the filters resulting from this project will continue to be published on the University of Alberta Libraries LibGuide, "Health Sciences Search Filters" and searchers are encouraged to look there for the most current versions. Searchers are encouraged to modify the filters for their own use and to incorporate local knowledge.

Future projects include rigorous testing of these filters, the creation of regional and national filters, and the creation of filters for other databases and platforms.

\section{Acknowledgements}

This research would not have been completed without the contributions of Iris Richardson and Caroline Lieffers.

\section{References}

1. Search Filters. Edinburgh, Scotland: Scottish Intercollegiate Guidelines Network (SIGN) [updated April 26, 2013; cited 
27 January 2014] Available from: http://www.sign.ac.uk/ methodology/filters.html.

2. Jenkins M. Evaluation of methodological search filters. Health Information and Libraries Journal, [Internet] 21 148-163, 2004. [cited 7 February 2014] Available from: http://onlinelibrary.wiley.com/doi/10.1111/j.1471-1842.2004. 00511.x/pdf.

3. Klatt MJ. An aid for total quality searching: developing a hedge book. Bulletin of the Medical Library Association [Internet]. 1994 [cited 7 February 2014] 82(10):438-41, Available from: http://www.ncbi.nlm.nih.gov/pmc/articles/ PMC225972/pdf/mlab00109-0098.pdf.

4. The Inter TASC Information Specialists' Sub-Group Search Filter Resource, [Internet] [cited 4 February 2014] Available from: https://sites.google.com/a/york.ac.uk/issg-search-filtersresource/home.

5. Pienaar E, Grobler L, Busgeeth K, Eisinga A, Seigfried, N. Developing a geographic search filter to identify randomised controlled trials in Africa: finding the optimal balance between sensitivity and precision. Health Information and Libraries Journal, [Internet]. 2011 [cited 7 February 2014] 28 210-215, Available from: http://onlinelibrary.wiley.com/ enhanced/doi/10.1111/j.1471-1842.2011.00936.x/.

6. Radut DS, Sanz-Valero, J. Developing and testing of search filters for the new European Union Member States' research. Health Information and Libraries Journal, [Internet] 27227 234, 2010 [cited 4 February 2014] Available from: http:// onlinelibrary.wiley.com/doi/10.1111/j.1471-1842.2010.00903. $\mathrm{x} / \mathrm{pdf}$.

7. Murray K. "[Filter] we're using to pull articles from PubMed for the Arctic health publications database". 20/06/2012; e-mail communication.

8. Sladek RM, Tieman JJ, Tyndall J, and Phillips, PA. Searching MEDLINE for Aboriginal and Torres Strait Islander health literature: questionable sensitivity. Health Information and Libraries Journal, [Internet]. 2013 [cited 7 February 2014] 30 138-148, Available from: http://onlinelibrary.wiley.com/ enhanced/doi/10.1111/hir.12018/.

9. Aboriginal health search filter (HLWiki) [Internet]. Vancouver, BC.: HLWiki International; 2013 [updated July 8, 2013, cited 2 February 2014]. Available from: http://hlwiki.slais.ubc. ca/index.php/Aboriginal_health_search_filter.

10. Kelly L, St. Pierre-Hansen N. So many databases, such little clarity: searching the literature for the topic aboriginal. Canadian Family Physician, [Internet] 54: 1572-3.e5, 2008 [cited 4 February 2014] Available from: http://www.cfp.ca/ content/54/11.toc.

11. Malyon R, Zhao Y, Oates B. Differences in the cost of admitted patient care for Indigenous people and people from remote locations. Australian Health Review. [Internet] 37 (1): 26-31, 2013. [cited 4 February 2014] Available from: http:// www.publish.csiro.au/?act=view_file\&file_id=AH11115.pdf.

12. Canada, National Household Survey. Table 2: Number and distribution of the population reporting an Aboriginal identity and percentage of Aboriginal people in the population, Canada, provinces and territories, 2011. [Internet]. Ottawa, Canada: Statistics Canada; 2011 [updated 24 April 2013; cited 4 February 2014]. Available from: http://www12.statcan.gc.ca/ nhs-enm/2011/as-sa/99-011-x/2011001/tbl/tbl02-eng.cfm.

13. Mueller-Alexander J, Seaton HJ. Researching native americans: Tips on vocabulary, search strategies and internet resources. Database, [Internet]. 1994 17(2), 45-46. [cited 2 February 2014] Available from: http://eric.ed.gov/?id=EJ481969.

14. Campbell S, Tjosvold L, Dorgan M, and Behn-Smith, D. Finding Canadian Polar Indigenous studies in Medline, Cold Regions: Pivot points, focal points: Proceedings of the 24th Polar Libraries Colloquy; June 11-14, 2012; Boulder, Colorado. Boulder, Colorado: NSIDC; [Internet]. 2013. [cited 2 February 2014] Available from: http://nsidc.org/pubs/gd/gd34/PLC-24-proceedings-GD-34.pdf.

15. Hobbema changes its name in the new year. Edmonton Journal [Internet]. 2013 December 25. [cited 7 February 2014] Available from: http://www.edmontonjournal.com/ technology/Hobbema + changes + name + year/9323420/story. html.

16. Centre for Reviews and Dissemination. Systematic Reviews: CRD's Guidance for Undertaking Reviews in Health Care Chapter 1. 3 Undertaking the Review. 2009. [cited 4 February 2014] Available from: http://www.york.ac.uk/inst/crd/Sys Rev/!SSL!/WebHelp/1_3_UNDERTAKING_THE_REVIEW. htm. 